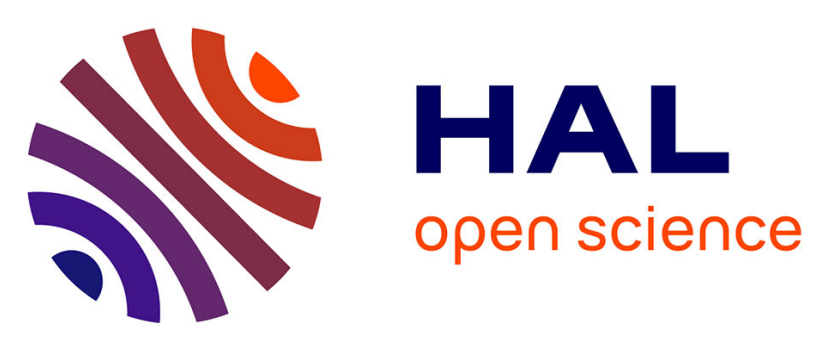

\title{
Is HIV prevention creating new biosocialities among gay men? Treatment as prevention and pre-exposure prophylaxis in Canada
}

Gabriel Girard, San Patten, Marc-André Leblanc, Barry D Adam, Edward Jackson

\section{To cite this version:}

Gabriel Girard, San Patten, Marc-André Leblanc, Barry D Adam, Edward Jackson. Is HIV prevention creating new biosocialities among gay men? Treatment as prevention and pre-exposure prophylaxis in Canada. Sociology of Health and Illness, 2018, 41 (3), pp.484-501. 10.1111/1467-9566.12826 . halshs-01930350

\author{
HAL Id: halshs-01930350 \\ https://shs.hal.science/halshs-01930350
}

Submitted on 21 Nov 2018

HAL is a multi-disciplinary open access archive for the deposit and dissemination of scientific research documents, whether they are published or not. The documents may come from teaching and research institutions in France or abroad, or from public or private research centers.
L'archive ouverte pluridisciplinaire HAL, est destinée au dépôt et à la diffusion de documents scientifiques de niveau recherche, publiés ou non, émanant des établissements d'enseignement et de recherche français ou étrangers, des laboratoires publics ou privés. 


\title{
Is HIV prevention creating new biosocialities among gay men? Treatment as prevention and pre-exposure prophylaxis in Canada
}

Gabriel Girard, San Patten, Marc-André LeBlanc, Barry D. Adam and Edward Jackson

\begin{abstract}
$\underline{\text { Abstract }}$
The advancements of "treatment as prevention" (TasP), "undetectable viral load" (UVL) and "pre-exposure prophylaxis" (PrEP) are redefining HIV prevention standards. Relying on the concept of biosociality, this article explores how gay men rally around, debate, and sometimes disagree about these emerging HIV prevention technologies. This article is based on data from the Resonance Project, a Canadian community-based research project. Twelve focus groups (totalling 86 gay and bisexual men) were held in three Canadian cities (Montreal, Toronto, Vancouver) in 2013-2014. Respondents view UVL and PrEP through the prism of their generational experience of HIV prevention. In this respect, biosocialities highlight an experiential dimension that is tied to the context of the HIV epidemic. The biosocialities of HIV prevention are also built around serological identities. However, our study shows the diversity of these positions. Analysis grounded in biosocialities is useful for better understanding how scientific information circulates, is made sense of, and generates debate among gay men.
\end{abstract}

\section{Introduction}

The use of antiretroviral therapy to prevent transmission is one of the major developments in the past decade in the field of HIV/AIDS. This approach has not only demonstrated its potential in terms of reducing risks, it also promises to transform the understanding of the danger and fear of passing on or acquiring the virus and, therefore, the implications of condomless sex. The concepts of "treatment as prevention" (TasP) ${ }^{1}$, "undetectable viral load" (UVL) ${ }^{2}$ and "preexposure prophylaxis" (PrEP) ${ }^{3}$ have the potential to redefine HIV prevention standards across public health responses, as well as at the community level and within relationships. In Canada, as in most industrialised countries, gay and bisexual men are particularly affected by these changes. Each year, this population accounts for over half of new HIV infections, particularly in large urban centres such as Montreal, Toronto and Vancouver. The social and political issues associated with the diffusion of the concepts of TasP and PrEP in gay communities have been

\footnotetext{
${ }^{1}$ Treatment as prevention refers to the use of antiretroviral therapy to suppress viral load among HIVpositive people, thereby preventing onward transmission of HIV.

${ }^{2}$ Undetectable viral load refers to an amount of HIV below the level that can be detected by current biomedical tests, typically 40 copies per $\mathrm{ml}$. There is now medical consensus that people with undetectable viral are untransmittable, although this statement was not as widely accepted the time of this study.

${ }^{3}$ Pre-Exposure Prophylaxis describes the use of antiretroviral medication by HIV-negative people, before sexual intercourse, in order to minimize the risk of being infected.
} 
discussed in a number of critical publications (Patton and Kim 2012, Rosengarten and Michael 2009). Biomedical developments in HIV prevention have also been approached from the perspective of the effects of these technologies on behaviours (Holt et al. 2013, Grace et al. 2014, Holt 2015), social relationships and/or cultural representations of risk (Grace et al. 2015, Young et al. 2015). This article focuses on how socialities are formed around new prevention technologies. Using the concept of "biosociality" developed by anthropologist Paul Rabinow, this article analyses the complex and changing relationships among biomedicine, biotechnologies and social relationships (Rabinow 1996, Rabinow and Rose 2006). This term refers to the formation of social relationships among individuals impacted or affected by the same health condition or disease (Rabinow 1996). Early work on biosociality centred on genetic issues around the Human Genome Project and sought to analyse how specific biological features could be the starting point for new kinds of relationships and mobilization among patients and their loved ones. The emergence of biosocialities is integral to analysing the impact of the mechanisms of power on life in contemporary societies (Rabinow and Rose 2006). Biopower is no longer systematically based on constraint, but mobilises selfefficacy and individual accountability. In the field of public health, such mechanisms are apparent in obesity prevention campaigns or breast cancer screening (Lupton 2013). Indeed, according to Rabinow and Rose, biopower involves population-based intervention strategies composed of, or based on, biosocial communities that may be specified in terms of race, gender, sexuality or genes. This theoretical perspective has been applied to various fields (Meloni et al. 2016). It has also led to an analysis of the political dimensions of biosocialities expressed in terms of "biological citizenship" (Petryna 2002), "biolegitimacy" (Fassin 2009) or "therapeutic citizenship" (Nguyen et al. 2007). These various approaches have shed light on the complex subjectivation processes, defined as "the forming of oneself as an ethical subject" (Foucault 1985, 28). Therefore, biosocialities and biosocial groups refer to "collectivities formed around a biological conception of a shared identity" (Rose \& Novas, 2005). If epidemiology and biomedicine define "at risk" or "vulnerable" situations and identities, the individuals and groups involved take on and interpret this objectivation work and contribute to shaping it (Hacking 1999).

This article draws on the Resonance Project, a community-based research project that was conducted in three Canadian cities (Montreal, Toronto, Vancouver) in 2013 and 2014. The purpose of the project was to gain a better understanding of how gay and bisexual men in Canada perceive, discuss and integrate the developments in HIV prevention in a context where TasP and PrEP continue to spark debate in gay communities.

\section{TasP, PrEP and debate about HIV prevention}

Since the beginning of epidemic, gay men's sexual behaviours and their adaptation to HIV risks have been the subject of multiple analyses (Kippax and Race 2003). Over time, gay communities developed various prevention strategies beyond condom use: reduction of the number of partners, frequent HIV testing, strategic positioning and negotiated safety. These techniques, 
which often emerged from gay cultures themselves, have been progressively used and rationalized by public health discourses. Since the late 1990s, in response to reduced condom use in gay communities, a broad field of scientific literature has been dedicated to the study of the development and implementation of biomedical prevention alternatives to condoms (Hart and Elford 2010). Relationships among sexual practices, community knowledge and scientific categorisations of risk are part of a long history (Race 2017).

Without question, the Swiss Statement, announced by Professor Hirschel and colleagues in late 2007, marked an important turning point in HIV prevention (Vernazza et al., 2008). Having observed zero infections in a cohort of heterosexual serodiscordant couples, the doctors stated that HIV-positive individuals with an undetectable viral load could not transmit HIV, provided they had been treated for at least 6 months, adhered to treatment, and did not have any STIs. In 2011, the HPTN052 study demonstrated the effectiveness of ART-related protection for serodiscordant heterosexual couples (Cohen 2011); in 2014 and 2016, the PARTNER study provided data on the effectiveness of undetectable viral load for serodiscordant heterosexual and same-sex male couples. In both studies, no infections occurred when the HIV-positive partner had an undetectable viral load.

Around the same time, another approach was being developed and tested: pre-exposure prophylaxis. The principle was not new: taking ART to prevent infection had been the basis for preventing perinatal transmission since the early 1990s. For "at-risk" men and trans women who have sex with men, three main studies took place to test daily - then intermittent - ART administration. In 2010, data from the iPrEx study demonstrated the strong potential for risk reduction with this strategy that was strongly correlated with adherence (Grant 2010, Grant et al. 2014). In 2014, the IPERGAY and PROUD studies confirmed the effectiveness of PrEP (McCormack 2016, Molina 2015) for prevention.

How these biomedical developments are affecting sexual interactions and risk management is not always straightforward. TasP has been studied as an area of new identity development among gay men (Race 2001) and undetectability is changing notions of the "normal" or "responsible" especially for HIV-positive men (Grace et al. 2015).

Redefining gay socialities in the context of antiretroviral therapy has been the subject of a significant amount of literature that highlights the transformation of community ties and growing individualism, but also the creation of new real or virtual peer networks (Race 2001, Davis 2008, Rowe \& Dowsett 2008; Holt 2011, Girard 2016). This article focuses on the understandings and perceptions about new HIV prevention technologies in focus groups of gay, bisexual and other men who have sex with men living in Canada. It deals with how gay men rally around, debate, and sometimes disagree with each other concerning these HIV prevention technologies.

The study of biosocialities examines how the subjects of biomedicine integrate, adhere to, or challenge the biotechnologies intended for them and this study shows the extent to which 
relationships of trust and scepticism vis-_a-vis expert knowledge translate into different modalities of belonging to an experiential community. Therefore, in this article, we aim to analyse biosocialities among gay men, in a context of a long-term epidemic. This involves focusing on the relationships created through HIV prevention but it also requires considering how individuals and their relationships are situated and enacted through biotechnologies. Our data show this double dimension.

\section{Methods}

The Resonance Project employed a community-based research (CBR) approach through all phases. In order to ensure that the Resonance Project reflected and represented gay men's perceptions, the team privileged their perspectives and interpretations throughout the research process. The research team included gay men, gay men's health service providers, educators from community-based organisations, biomedical prevention technology experts, public health experts and representatives of the collaborating organisations. The research team provided advice related to the research design, including development of research tools, participant recruitment, data collection, data analysis, interpretation and dissemination through various knowledge exchange methods.

\section{Participants}

The Resonance Project gathered perspectives of gay men through four focus groups with gay men in each city (Vancouver, Toronto, Montreal), for a total of 12 focus groups. The choice of focus group method aimed to create the conditions for discussion and debate among gay and bisexual men in order to better understand how their arguments are developed.

Above is a table summarising the inclusion criteria for the focus groups. All participants had to be at least 18 years old, to identify as cisgender or transgender men, and to have been sexually active with men in the last 6 months. Focus groups were recruited purposively to engage men with potentially different relationships to new prevention technologies: men who had contact with AIDS service organisations (ASOs) and those who did not, men in serodiscordant relationships who were managing everyday HIV prevention, sexually active HIV-positive men, and men at elevated risk of HIV but who had no formal contact with ASOs (Table 1).

\section{Recruitment}

The local partners - Health Initiative for Men (HIM) in Vancouver, REZO in Montreal and Gay Men's Sexual Health Alliance (GMSH) in Toronto - recruited participants for the focus groups in ways that were adapted to the local gay scene. Each city developed its own recruitment 
materials, based on a common template (see poster/card graphics below). Recruitment posters and ads were posted in various physical and virtual spaces, including clinics, bars, bathhouses, coffee shops, websites, social media and hook-up sites. Outreach workers and volunteers they enlisted found participants in community venues, such as social clubs, gay men's health clinics, at community meetings and events, bars, bathhouses and outside subway stations.

There were also more targeted efforts for identifying potential participants for specific focus groups. The table below summarises the number of gay men who participated in focus groups across the three cities (Montreal, Toronto and Vancouver) (Table 2).

Table 1: Inclusion Criteria for Focus Group

\section{Inclusion Criteria for Focus Groups}

Focus Group 1: gay men

connected to HIV

organizations

Focus Group 2: gay men

in serodiscordant

relationships

Focus Group 3: sexually

active HIV-positive gay

men

Focus Group 4: HIV-

negative gay men at

'high risk'
- Attended a workshop, training or conference on HIV in the past year

- HIV-negative or HIV-positive

- Currently in relationship of more than 6 months

- Partner's HIV status is different than theirs

- Has ever received a positive HIV test result

- Has had sex with >1 man in past 3 months

- Has never received a positive HIV test result

- Has been tested for HIV more than twice in last year and/or has used recreational drugs in past 3 months

- Has had sex with >1 man in past 3 months

Table 2: Total Number of Participants in Focus Groups

\begin{tabular}{|c|c|c|c|c|}
\hline \multicolumn{5}{|c|}{ Total Number of Participants in Focus Groups } \\
$(\mathrm{FG} 1, \mathrm{FG} 2, \mathrm{FG} 3, \mathrm{FG} 4)$ \\
\hline & FG2 & FG3 & FG4 \\
\hline City & FG1 & FG & 5 & 12 \\
\hline Vancouver & 8 & 6 & 5 &
\end{tabular}




\begin{tabular}{|r|c|c|c|c|}
\hline Toronto & 11 & 5 & 8 & 9 \\
\hline Montreal & 10 & 2 & 5 & 5 \\
\hline Total & 29 & 13 & 18 & 26 \\
\hline $\begin{array}{r}\text { Total \# of } \\
\text { unique }\end{array}$ & \multicolumn{3}{|c|}{86} \\
$\begin{array}{r}\text { individuals } \\
\text { indival }\end{array}$
\end{tabular}

The figures below show the demographic characteristics of the men who participated in the study (Fig. 1 and 2).

Figure 1: Demographic characteristics of participants : City, serostatus an age
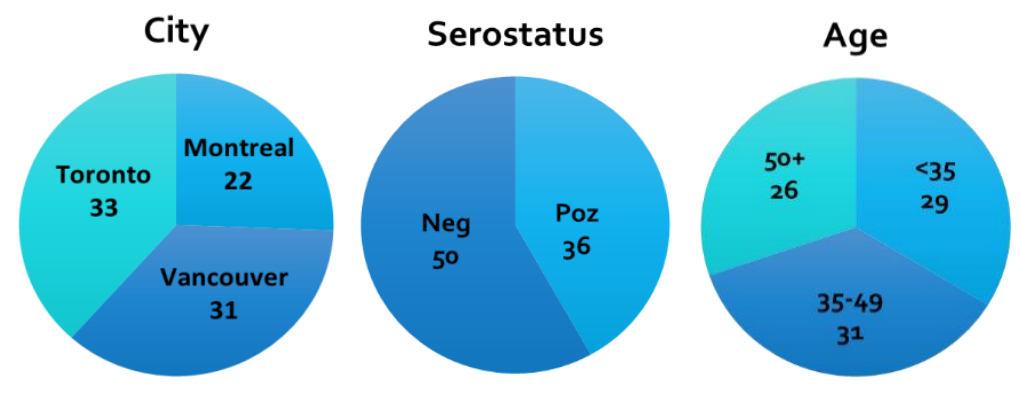

Figure 2: Demographic characteristics of participants : Ethnicity

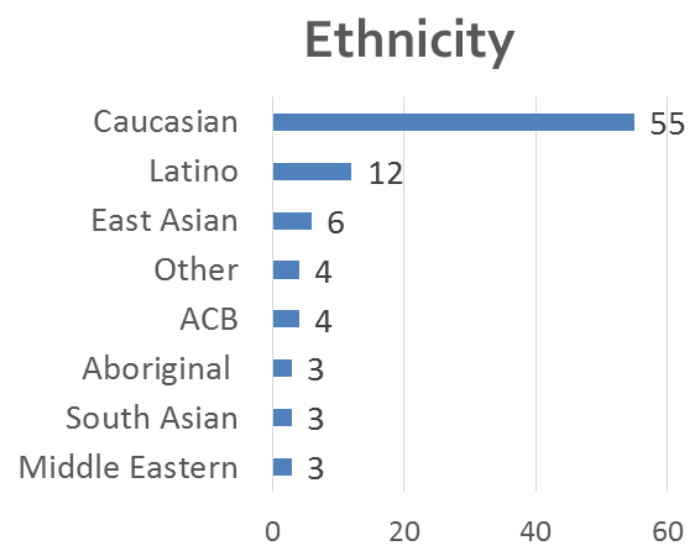

\section{Focus group methods}

The focus group guide was developed collaboratively by the research team to cover the following topics: what biomedical information gay men are hearing and from whom; level of interest in biomedical technologies such as home testing, PrEP and Post-Exposure Prophylaxis 
$(\mathrm{PEP})^{4}$; types of biomedical logic and reasoning that they are using; barriers to using biomedical approaches to prevention; and how biomedical knowledge of HIV informs their risk calculations. Rather than directly ask the focus group participants about their knowledge levels and how they know what they know in relation to the biomedical concepts, mock online profiles Table 2 Total number of participants in focus groups from common hook-up sites/apps, dating scenarios, and real media headlines were used to stimulate conversations to see how study participants would react, for example, to prospective partners who indicate they bareback, are undetectable, or are taking PrEP. Focus groups in Vancouver and Toronto were conducted in English; in Montreal in French.

\section{Analysis}

Once cleaned of identifiers, the transcripts were loaded into NVivo10. Data analysis was conducted by a subgroup of the research team, namely the co-authors of this article. Using a process of interpretive description (Thorne, 2008), the authors repeatedly read the data to confirm, test, explore, and expand on the key concepts and patterns, emerging themes, indicative examples from the data, and connections to relevant theoretical perspectives. We analysed collectively a sample of focus groups (from different cities and focus group types), in order to establish a coding scheme. Two members of the subgroup then coded all the transcripts, allowing all co-authors to proceed to a collective reading and analysis of the entire coded data, leading to article writing. As part of a commitment to critical discourse analysis, we also analysed the use of language and metaphors to uncover interpretations of biomedical knowledge of HIV. The inductive process for thematic analysis, drawing on Boyatzis (1998), included developing a coding scheme for organising segments of similar or related texts; identifying initial themes; applying the codes from the coding scheme to the text with the intent of identifying meaningful units of text; and finally, connecting codes and developing additional themes.

\section{Results}

The focus groups discussed in depth two of the most recent prevention technologies: preexposure prophylaxis (PrEP) and undetectable viral load (UVL). The level of knowledge and understanding of these two approaches was heterogeneous according to type of focus group, but also according to city, HIV status and age. There seemed to be a better understanding of PrEP among Montreal participants, possibly because of the IPERGAY study, which began in 2013 in Quebec, but also due to ongoing advertisements about PrEP published by private clinics in the community press. In Montreal, two participants were taking PrEP and mentioned this during the

\footnotetext{
${ }^{4}$ Post-Exposure Prophylaxis is a preventative tool consisting of taking anti-HIV drugs for 1 month after a potential exposure to HIV.
} 
focus groups. There seemed to be a higher level of knowledge of UVL in Vancouver, possibly because British Columbia health authorities actively promote TasP as a strategy. Otherwise, participants had highly variable levels of knowledge: some were discovering the strategies for the first time within the focus group; others had heard of them but were not able to define them with certainty; while still others were able to explain how they worked by referring to the scientific data.

\section{Mapping of social and moral risk}

PrEP and UVL contribute to redefining the concept of sexual risk by introducing the possibility that condomless sex does not necessarily mean exposure to HIV. In focus group discussions, participants expressed their views about norms of responsibility for HIV prevention; PrEP and UVL led some participants to reposition or reaffirm their values regarding risk.

\section{Risk reduction and responsibility}

In the focus groups, discussions about PrEP inevitably triggered debate about responsibility with respect to HIV risk. Some participants expressed skepticism concerning the motives for taking PrEP while others viewed PrEP as both rational and responsible. Claim about the lack of responsibility of "others" was often a way to define a moral boundary between "good" and "bad" subjects with respect to prevention.

Participant A ( Neg, $<35, \mathbf{M} 4)$ : I find that people see this anti-HIV pill as a pretext for not using protection. A miracle pill not to protect yourself, exposing yourself to risk of infection. . This makes no sense to me. (All excerpts from Montreal (M) groups are translated from the French.)

Participant B (Neg, <35, M1): I'm sorry but I am on PrEP myself and I am not a case of "I bareback every week." I saw a doctor and had a discussion with her and it was at my request that she prescribed it to me.

Participant C (Pos, 50+, M1): They are not all like you.

In these last two excerpts, two participants express, each in his own forceful way, a suspicion about PrEP users. Even when another participant (B) taking PrEP speaks up to explain his own risk relationship, the speaker singles him out as being unique among a group of men who are perceived as reckless and irresponsible. A number of participants feel that PrEP is still a minority strategy and is "not very well regarded in the community", as was expressed by another man who is also taking PrEP (Participant D, Neg, 35-49, M2). In Montreal, PrEP use was starting to increase when the focus groups were conducted (January 2014), but it remained limited. 
In the three cities, discussions about PrEP led the participants to position users of this strategy in terms of responsibility criteria but assigning this responsibility did not necessarily mean moral disapproval. For a number of men, PrEP was considered an affirmation of a fulfilling sex life:

Facilitator (F): If you met somebody or you heard that somebody was on PrEP, what comes to mind about that person? What are your preconceptions maybe about that person?

Participant E (Pos, $50+$, V2): They're probably a bit like me.

F: What does that mean?

Participant E: It means that they want to have the possibility of unprotected sex, a bit like me. S-L-U-T.

In this excerpt, the technology creates an affinity around the idea of sexuality that is free from the requirements of conventional prevention. In another vein, some participants position PrEP as a potential guarantee of a responsible approach to managing one's health.

Participant F (Pos, 50+, V3): It would just prove to me that they're being responsible if they're sexually active. If they're on PrEP they're probably getting tested on a regular basis too. The people that take PrEP aren't the ones that never get tested I would imagine, I would think. I would hope. The people on PrEP are the ones that probably would be getting tested regularly because they're taking responsibility for their health...

F: If you hear somebody is on PrEP, does it come with any. . you put it in a positive light - that they're being responsible. Does it come with any negative baggage at all for anyone?

Participant G (Pos, 35-49, V3): I kind of wonder how much sex they're having. But it really doesn't matter. Who am I to judge? I'd like to have a lot of sex too.

$(\ldots)$

Participant H (Pos, 35-49, V3): I just think that they are being very responsible with their health. For some reason I'd also feel more comfortable with them because they're knowledgeable and they know about prevention and they're aware, they're up to date, they're modern.

The range of reactions about PrEP points to the fact that this prevention technology is emerging in an existing moral context. For some participants, PrEP translates into a concern for self and others, providing reliable protection while allowing sexual liberation. Other participants feel that this strategy promotes sexual freedom at the expense of sexual health. The latter placed condom use on a higher moral plane than PrEP use. 
Undetectable viral load also presents moral dilemmas. For HIV-positive men, the risk of exposing an HIV-negative partner triggers intense reflection, given the context of criminalization in Canada (Adam et al. 2014). Within the focus groups, this concern was sometimes expressed as self-justification in the face of the assumed judgement of other participants:

Participant I (Pos, <35, M3): I'm going to go a bit opposite to the group, but personally, what this information tells me, it's simply that indirectly, I tell myself that if I have sex with someone who does not use protection. . . I did not force him. So we did not necessarily talk about our status or anything, but we had exciting sex, and as we get into sex. . . I tell myself. . . I am going to do it without feeling persecuted, like I was a criminal or a killer because I know that I have an undetectable load, I'm really good about my meds, it's been 3 years that I've been undetectable every time I do a blood test every 3 months. I know the risk of transmission is low, so that means I will go ahead with unprotected sex. But I will cum outside his ass though. . . that's my gauge. So after, in terms of my ethics, is this good or bad? I don't know, we could talk about this if you want, put me on trial.

This man expresses his interpretation of responsibility with respect to TasP: because he has an undetectable viral load, he feels he is not putting his partners at risk. Therefore, it is up to them to ask about using a condom. The normative tension is explicit here in his discourse and his use of the expressions "feeling persecuted, like I was a criminal" and "put me on trial".

On the other hand, another HIV-positive participant reaffirms an interpretation of prevention based on avoiding situations with risk.

Participant E (Pos, 50+, V2): Then sometimes you start to get through that little bit of the conversation which is sex possible. . . if you're HIV negative, I'm going to think two or three times before I touch you. I watched a lot of people die. When I have made an error that way and it's happened once or twice, it has cost me weeks of depression. I feel like a gatekeeper in a way. I feel like every time I do it with another positive guy, bareback or not, in Darwinian terms I'm selecting for a weaker strain of the virus, just like if you use a condom or whatever else. That's the harm reduction. Now they're talking about undetectable viral loads. I wouldn't still. I wouldn't want to put a negative guy at risk.

By refusing to have condomless sex with his HIV-negative partners, this man is responding to his own moral imperative. Following a very strict prevention approach for him is consistent with the experience of the dark years of the epidemic.

In the focus groups, the issue of assigning responsibility was the topic of much discussion. Participant views were based on pre-existing moral conceptions that guide their understanding of prevention choices (Davis 2008, Rangel and Adam 2014). These conceptions cannot be disassociated from the trajectory and perception of risk or the definition of a fulfilling sex life. Conflicting views expressed in the focus groups reflected different decisional processes related 
to these aspects. With TasP and PrEP, these differences are not necessarily based on HIV status. The experience of risk - condomless sexual practices or a partner with a different HIV statuswas then part of redefining preventive biosocialities (Grace et al. 2014). Biosocial groups appear to be anchored in different conceptions of sexual authenticity in times of HIV epidemics. Here, we can clearly see the twofold process: the appropriation of biotechnologies to redefine preventive interactions, and the very notion of responsibility, and how incorporating these technologies produces "healthy sexuality" as a new moral imperative.

\section{Undetectability: Areas of uncertainty}

In comparison to PrEP, participants were more familiar with the protective effects of undetectable viral load (UVL). This did not however preclude disparities within the groups or geographic differences. The Vancouver groups were on the whole better informed, which can be explained by the active policy of the province's health authorities promoting TasP as a strategy.

However, in each of the three cities, some participants became aware of the concept of UVL within the focus group:

F: Had everyone seen that term before and knew what it was before tonight? Or is this something new tonight?

Participant J (Neg, 35-49, V4): I'm a bit embarrassed to say that I never heard of it.

Participant K (Neg, <35, V4): I never heard about undetectable.

P: I heard of it but I don't necessarily understand it.

P: I'll admit too, I had no idea.

These are minority situations but they show the heterogeneous nature of the gay community with respect to information about prevention. More generally, knowledge and lack of knowledge about UVL were components of discussions in the groups. These exchanges often involved the level of information among people other than themselves: other members of the gay community, sexual partners or users of hook-up sites.

Participant L (Pos, $<35, \mathbf{3 1}$ ): On the Internet especially, if you say the word HIVpositive, people are more. . . hmm. ... The minute you say healthy and undetectable, it's becoming more of 'okay what is undetectable? Can you explain that to me?' Some people don't really know. The problem is the information out there is not, in my opinion, not clear enough to define what undetectable is.

(..) 
Participant M (Pos, 35-49, T1): There are still a lot of people out there that don't know what undetectable means.

Participant N (Pos, 35-49, M2): Most people don't know this. When you say undetectable viral load, people ask, is that a recipe for baking a cake?

Participant D (Neg, 35-49, M2): Yeah, it's true that not everyone knows about it. That's true.

Participant N: Not everyone. They'll ask, what's that? They'll say, is that undetectable lubricant that you can't feel? What's that, what does that mean? They won't find you with their GPS? HIV-negative partners know about it because their boyfriend is HIV positive.

In these two dialogues, the lack of knowledge about the strategy is attributed to lack of information about the subject. However, one of the Montreal participants also points out how knowledge of this approach cannot be separated from the biological and relational experience of HIV, such as being part of a serodiscordant couple. Other participants suggest that knowledge of UVL is indicative of an unequal distribution of knowledge about prevention even within the gay community:

Participant B (Pos, <35, M1): In Montreal, I would say that in the Village, everyone knows what undetectable is. When you go beyond that area, when I say I'm a poz undetectable guy, then you get a bunch of question marks. I don't even take the time anymore to explain because it's too long and ultimately, the person will still be extremely afraid and then not understand what it was. There are truly two realities I find, in the Village and then outside of the Village in other areas.

Here, the lack of knowledge about UVL defines a geographic divide between "the Village" and the urban periphery. These spatial issues can also be part of the biographical trajectory, as with this Vancouver participant who explains his own journey in terms of UVL:

Participant $\mathrm{O}$ (Neg, 35-49, V2): I actually didn't even hear about undetectable viral load until I moved here. Then I learned it from him [his partner]. I did a lot of research. I went to the web and looked up everything I could and spoke to some health professionals at the HIM [clinic] $]^{5}$. They all said the same thing; having sex with somebody that is known to have low viral load is safer than having sex with a stranger with a condom. I couldn't believe that they were all saying the same thing. Wow. So I started having unprotected sex with him [HIVpositive partner]. I'm always the top. That's the stipulation.

In this case, the integration of information is directly related to a change in environment and access to community outreach. These two examples show the spatial dimension of biosocialities

\footnotetext{
${ }^{5}$ Health Initiative for Men (HIM) is a community-based organization in Vancouver.
} 
in HIV prevention. However, knowledge of new technologies such as UVL aligns with participation in a community experience (Friedner 2010).

\section{Undetectability and self-identification}

For a number of participants, achieving undetectable viral load means a new relationship to the self and to others; namely being defined as "undetectable" instead of simply as "positive" or "HIVpositive". In the first focus group of the study, one of the men made this very clear statement:

Participant F (Pos, $\mathbf{5 0}+, \mathbf{V} \mathbf{3})$ : I always say undetectable is the new negative.

F: In what ways and why?

Participant F: Just because it's just low risk, next to no risk.

Here, undetectability is placed on equal footing with absence of risk; in broader terms, it removes the need to be identified with HIV. In the subsequent focus groups, we introduced the expression "Undetectable is the new negative" to other participants in order to generate discussion about these self-identification implications, especially during online cruising. The statement led to much debate during the focus groups:

F: Participant D, What do you think about 'undetectable is the new negative'?

Participant D (Neg, 35-49, M2): Well, as far as I know, there is no such thing. Unless this is a question of ... it's me who is not aware, that I missed something there. But positive undetectable, that's one thing. Positive, that's another thing. And then negative, that's another thing. You can't stick your head on the sand. Although yes, the risk is minimised, even nearly impossible, but if you forget your medication one day then everything is wiped out and you start back at zero.

Participant P (Pos, $50+, \mathbf{T 3}$ ): Undetectable, a lot of people think, oh I'm never going to infect, I'm never going to get infected, or I'm never going to infect anybody else so therefore, get rid of the condoms now because you're undetectable and I'm undetectable. But there's still that less than $.05 \%$ that you are. People seem to have this belief that you're safe again or that they can play unsafe and not worry about it.

Far from building a broad consensus, the statement, "Undetectable is the new negative," revealed a series of conflicting views within the groups, both among HIV-negative and HIVpositive participants with regard to assessing risk statistics or the credibility of scientific sources. As shown in other research, undetectability reinforces the feeling of responsibility on people living with HIV (Grace et al. 2015). Undetectability allows some respondents to 
renegotiate their relationships to others. However, for some, it seems that UVL does not tie into an identification process, because unstable biological data are involved.

\section{Refusal and criticism of medicalisation: other biosocialities}

For some participants, new prevention technologies generate skepticism, fear, or rejection. This criticism also illustrates other forms of biosocialities whose legitimacy is rooted in values, individual and collective histories, or adherence to other, older prevention tools (condoms, for example). Analysing these discourses of defiance-which sometimes extend to conspiracy theories-as forms of biosociality allows for another way to consider the tensions around biomedical innovations (Callon and Rabeharisoa 1999, Raman and Tutton 2010).

PrEP, a risk technology?

Throughout the groups, there was a great deal of criticism and reluctance with respect to PrEP. Fears about the potential toxicity of antiretroviral treatments (ART) for uninfected people came up consistently in the concerns voiced, particularly by HIV-positive men and by HIV-negative men who have (or had) someone close to them living with HIV:

Participant Q ( Neg, $50+$, V1): Part of what would not make PrEP a choice for me at this point in time is that it's fairly new and we don't know what it does to the body in the long term to a healthy immune system because of the toxicity of the drugs. We all know that. Whenever somebody goes on a new regimen of drugs, you have to go through that adjustment period. The toxicity, in spite of people's longevity with HIV these days, is still there. That to me is not a desirable thing if I don't need it. We don't know what the long-term impact of that is yet, at least I don't.

Participant R (Pos, 35-49, T3): But I think it definitely leads to a false sense of security because how long will it be before you know in 50 years a study finds out that this stuff is actually causing liver damage or something else that we weren't aware of? Then it's 50 years down the road too late.

Some fear that PrEP raises a false sense of security, a concern rooted in generations of gay men that experienced the long-term effects of the earlier sets of anti-HIV drug treatments on the body. This echoes several critical discourses about "over-medicalisation" in modern societies. On a related note, criticism of the pharmaceutical industry came up regularly in the groups with respect to PrEP:

Participant I (Pos, <35, M3): So for me, this raises ethical issues with respect to the pharmaceutical companies that make huge profits in selling the drugs and ultimately now we don't just have HIVpositive guys taking medications but now HIV-negative guys 
as well. Similar treatments. Ok, I don't know if there are as many taking them as those who are HIV positive but... it's become a way for not transmitting HIV. That's ok fine, I don't know. . . I don't know what kind of world we're heading toward.

For Participant I, the pharmaceuticalisation of prevention for people who are HIV-negative is part of uncontrollable changes in a world led by profit motives. In the same vein, users of PrEP were sometimes described as laboratory animals in terms of the potential risks.

Participant $\mathrm{O}$ ( $\mathrm{Neg}, \mathbf{3 5 - 4 9 ,} \mathrm{V2}$ ): And that's one of the reasons I chose against it. I'd be taking on a lot of risk by taking the drugs when I didn't feel like I was in an unsafe situation to begin with. Once it's been out maybe 10 years, I might consider it then when all the effects are known. But right now it's just too new. I don't want to be one of the guinea pigs.

As noted above, PrEP users were sometimes perceived as responsible individuals who care about their health. In other cases, they were seen as irresponsible.

Participant S (Pos, <35, V2): And then also from a health standpoint if PrEP is available to anyone who wants to take it, does that mean you've got a bunch of guys who think they're totally invincible and they're going to go fuck their brains out? Or are they going to do that anyways? I wish that we had PrEP for my personal situation.

In this case, there is evident ambivalence. In this instance, PrEP is understood as an incentive for risk that could potentially weaken the use of condoms. Yet at the same time, Participant $S$, an HIV-positive man under 35 years of age in a serodiscordant relationship, voices regret about not having had access to it. In this case, PrEP represents the possibility of greater intimacy (and/or less anxiety) with his negative partner. It opens up the possibility of imagining a sex life without condoms and without risk, which calls into question the many years of preventive socialisation.

\section{Undetectability: Limits and pitfalls}

In discussions about undetectability, a number of participants expressed skepticism or doubt. This resistance is partly explained by the lack of clarity of community and public health organisations in their public communications about UVL. This fact is clearly illustrated in the following excerpt:

Participant T (Neg, 35-49, M4): There has been information about it going around for a few years now and at first I was skeptical and wondering 'Is that a lie? You can't find anything written about it almost anywhere else. Is this information boycotted? Is it censored?' Because it started to come out in late 2011, these stories. It came from Switzerland. They were saying that 'for people who have an undetectable viral load and take their meds regularly, the risk of transmission is almost nil.' Well, this information 
was well kept. We were wondering how can we even know if it's true? No one is passing it on. Where is this coming from? Is this reliable? So that's still the situation today.

But other forms of reluctance are expressed, around the biomedical limits - real or assumed -of this strategy. This is particularly the case for issues of superinfection by strains that are resistant to treatments. For the participant below, the discussion about superinfection is the opportunity to bring up his difficulty navigating through medical information that is often alarmist:

Participant L (Pos, <35, T1): Even as a positive person we used to... you know the scare was put into us by our doctors that if you have unsafe sex you're going to get another strain probably. Superinfection is an old concern in the gay community (Adam et al. 2005). Since the Swiss Statement, it garners only a low level of attention in the medical literature, but it remains in the discourse of HIV-positive men. Lastly, a number of participants shared their concerns about the potential for "trivialising" risk with new prevention technologies, and particularly with UVL.

Participant B (Pos, <35, M1): The term undetectable, I agree with you, that trivialises the risks of transmission, enormously.

Participant I (Pos, <35, M3): So what also happens with this famous undetectable status, it's that it becomes the key to have any kind of sex when and where you want. But did I take a blood sample and test it to find out if you were truly undetectable or if you had your viral load was through the roof? ... We take that at face value, but unless you really know the person and then know that you can have a relationship of trust with him, if the person says the magic words, it's not a reason for having sex without a condom, you know.

Here, managing HIV prevention in everyday life becomes a problem of verifiability: can one rely on the other's claim to undetectability? Although UVL is a factor in alleviating the anxiety about transmission, this information did not result in major changes in prevention practices with these two HIV-negative participants:

Participant $\mathrm{U}(\mathbf{N e g},<35, \mathbf{V 4})$ : It hasn't changed my practice but it's planted some confusion, or not confusion, but it's kind of like, well maybe it would be safe. But I think in my mind first and foremost it's highly engrained in me to always use a condom. So it hasn't changed my practice but the messaging makes me wonder a little bit.

Participant V (Neg, <35, V4): For me the same. It didn't change my practice but at the same time it gives me a bit more peace of mind because when we talk about the risk there is not any definite number. It's always like a range. It minimises the risk so it's good. But I still have my practice. I still use the condom but well it is less risk.

Critical discussion around undetectability highlighted the social and cultural conditions for the adoption of scientific data (Hacking 2006). In the various groups, participants voiced their concerns about a "paradigm shift" that is underway, a shift they have perceived in online hook- 
up sites, where undetectability now appears in user profiles. "Paradigm shift", a term largely used in recent HIV prevention discourses, refers here to the transition from condom-centred prevention to a context where new highly effective biomedical tools are also available. But, this new context also rekindles deep-seated fears about risk and verifiability. In this respect, the residual risk seems off-putting to a number of participants who also express distrust of biomedicine.

\section{Discussion}

The data from the Resonance Project shed a unique light on the dynamics of the diffusion of new HIV prevention technologies in the gay community. The shift in prevention norms has already been addressed in various reviews that highlight growing individualisation, but also the continuity of forms of collective solidarity in the gay community (Rowe \& Dowsett, 2008; Davis 2008, Girard 2016). An analysis grounded in biosociality offers a different framework, by focussing on how new prevention technologies contribute to the redefinition of these social relationships.

The analyses outlined in this article have a number of limitations. First, the Resonance Project data were collected in late 2013 and early 2014. Since then, scientific and community debates surrounding topics such as PrEP and undetectability have continued to evolve, landing on much broader consensus about their high level of efficacy. Second, while the focus groups allow for the dynamics of the debates to be recorded, they also reproduce the power relationships between the speakers. Despite attempts to ensure that the voices of younger and non-white participants were heard - through facilitation techniques - overall the data collected nevertheless generally reflect the predominant voices of older white men. Due to this limitation, we need to be careful about generalising the results.

There were three key learnings that came out of the data.

- First of all, the respondents seem to view UVL and PrEP through the prism of their generational experience of HIV prevention. Within the Resonance Project, disparities arose according to when the participants initially became sexually active. This finding is in line with the AIDS generations analysis developed by Hammack et al. (2018). Having experienced the emergence of HIV and the harm it caused in gay communities does not necessarily lead to a critical position with respect to treatment as prevention. As we have observed, these positions vary. However, the data point to the weight of sexual and preventive socialisation. For some respondents, developing their sexuality in an environment where condoms were a central prevention tool for several decades has conditioned the acceptability of alternative risk reduction techniques. In this respect, biosocialities highlight an experiential dimension that is tied to the context of the HIV epidemic. 
- The biosocialities of HIV prevention are also built around serological status. However, our study shows the diversification of these positions. Testing draws a biomedical boundary between HIV-positive men and HIV-negative men. Greater complexity is introduced with treatment as prevention. Some men living with HIV are claiming undetectability as a new means of self-identification. Likewise, new biological socialities are being developed in light of PrEP. A number of respondents who are reticent about this new tool consider that those taking PrEP are making light of or are unaware of the adverse effects of treatments. This critical view touches on an underlying commonality among HIV-positive respondents taking antiretroviral treatments and HIV-negative respondents who have someone close to them taking antiretroviral treatments. This pharmaceutical solidarity may be situational and tied to the time the data were collected, when the effectiveness of PrEP was being widely discussed. It nevertheless reveals a shift in biological socialities.

- Analysis grounded in biosocialities is also useful for better understanding how scientific information circulates, is made sense of, and generates debate among gay men. These issues around information flow are particularly evident when respondents discuss remaining areas of uncertainty. For instance, for some, we noted the lack of knowledge of biomedical information related to geographic or symbolic boundaries: the fact of living outside of urban centres or outside of the "Gay Village". However, the disagreements expressed in the focus groups draw attention to reluctance or distrust with respect to new prevention technologies as a foundational element of biosocialities. While biosocialities are often studied within the framework of integrating and adhering to scientific innovations, this research shows the usefulness of having a better understanding of the potential solidarities expressed in the resistance to prevention biotechnologies. The idea is not to take sides but to consider properly how references to "old" approaches (such as the condom) can be the basis for social relationships, just as enthusiasm for new technologies can be. This is especially important to consider in a context where condom use has been such a pervasive and ubiquitous HIV prevention message, and the emergence of PrEP and UVL presents a major cultural shift that forces an expansion of moral reasoning around responsibility, risk-taking and risk-reduction.

Our use of the concept of biosociality differs in many respects from its classical uses. In this paper, relations and identities are observed "in the wild" (Callon and Rabeharisoa 2003), outside the context of clinical or laboratory research, so the issues of biosocialities raised here engage more directly with the research field on the pharamaceuticalisation of society (Williams et al. 2011). Our work highlights how relationships between service providers and users/patients, and relationships among gay men, are being reshaped by pharmaceutic interventions. These are processes that contribute to a "colonisation" of everyday life by pharmaceutical solutions, where biosocialities shed light on the heterogeneous processes of the reconfiguration of HIV prevention in Western gay communities. 
In a cross-sectional view, this article reveals the extent to which issues of individual responsibility regarding transmission risk are the backdrop for debate among the focus group participants. Taking risks (or having another take them) remains a central aspect of the moral framework that structures discourse around HIV prevention (Race 2017). It is difficult to say at what point new prevention technologies will reconfigure this situation but these technologies already allow some individuals to renegotiate their place in this moral context. By providing the possibility of safe and condomless sex, TasP and PrEP drastically change how HIV prevention is perceived. There is enthusiasm along with resistance, suspicion, criticism and concern with respect to long-term prevention changes. Individual history, experience with HIV, generation or the level of trust in the expert discourse are some of the factors that explain these differing attitudes. In light of TasP and PrEP, HIV prevention remains a controversial issue, as it affects the normative dimensions of intimacy.

\section{Acknowledgements}

The authors would like to thank all the participants of the project, CATIE and the Resonance Project

\section{$\underline{\text { References }}$}

Adam, B., Husbands, W., Murray, J. and Maxwell, J. (2005) Risk construction in reinfection discourses of HIV-positive men, Health, Risk and Society, 7, 1, 63-71.

Adam, B., Elliott, R., Corriveau, P. and English, K. (2014) Impacts of criminalization on the everyday lives of people living in with HIV in Canada Sexuality Research and Social Policy, 11, 39-49.

Boyatzis, R. (1998) Transforming Qualitative Information. Thematic Analysis and Code Development. Cleveland: Sage.

Callon, M. and Rabeharisoa, V. (1999) La lec_on d’humanit_e de Gino, Réseaux, 17, 95, 197-223.

Callon, M. and Rabeharisoa, V. (2003) Research "in the wild" and the shaping of new social identities, Technology in Society, 25, 193-204.

Cohen, M., Chen, Y.Q., McCauley, M., Gamble, T., et al. (2011) Prevention of HIV-1 infection with early antiretroviral therapy, New England Journal of Medicine, 365, 493-505.

Davis, M. (2008) The "loss of community" and other problems for sexual citizenship in recent HIV prevention, Sociology of Health \& IIIness, 30, 2, 182-96.

Fassin, D. (2009) Another politics of life is possible, Theory Culture Society, 26, 5, 44-60. 
Foucault, M. (1985) The History of Sexuality. The use of pleasure: London, Penguin Books.

Friedner, M. (2010) Biopower, biosociality, and community formation: how biopower is constitutive of the deaf community, Sign Language Studies, 10, 3, 336-47.

Girard, G. (2016) HIV risk and sense of community, French gay male discourses on barebacking, Culture Health and Sexuality, 18, 1, 15-29.

Grace, D., Chown, S.A., Jollimore, J., Parry, R., et al. (2014) HIV-negative gay men's accounts of using context-dependent sero-adaptative strategies, Culture Health and Sexuality, 16, 3, 31630.

Grace, D., Chown, S.A., Kwag, M., Steinberg, M., et al. (2015) Becoming "undetectable": longitudinal narratives of gay men's sex lives after a recent HIV diagnosis, AIDS Education and Prevention, 27, 333-49.

Grant, R., Lama, J.R., Anderson, P.L., McMahan, V., et al. (2010) Preexposure chemoprophylaxis for HIV prevention in men who have sex with men, New England Journal of Medicine, 363, 27, 2587-99.

Grant, R., Anderson, P., McMahan, V., et al. (2014) Uptake of pre-exposure prophylaxis, sexual practices, and HIV incidence in men and transgender women who have sex with men: a cohort study, The Lancet Infectious Diseases, 14, 9, 820-9.

Hacking, I. (1999) The Social Construction of What? Cambridge: Harvard University Press.

Hacking, I. (2006) Genetics, biosocial groups \& the future of identity, Daedalus, 135, 4, 81-95.

Hammack, P.L., Frost, D.M., Meyer, I.H. and Pletta, D. (2018) Gay men's health and identity: social change and the life course, Archives of Sexual Behavior, 47, 1, 59-74.

Hart, G. and Elford, J. (2010) Sexual risk behaviour of men who have sex with Men: emerging patterns and new challenges, Current Opinion in Infectious Diseases, 23, 1, 39-44.

Holt, M. (2011) Gay men and ambivalence about 'gay community': from gay community attachment to personal communities, Culture Health and Sexuality, 13, 8, 857-71.

Holt, M. (2015) Configuring the users of new HIV-prevention technologies: the case of HIV preexposure prophylaxis, Culture, Health \& Sexuality, 17, 4, 428-39.

Holt, M., Murphy, D., Callander, D., Ellard, J., et al. (2013) HIV-negative and HIV-positive gay Men's attitudes to medicines, HIV Treatments and Antiretroviral-Based Prevention, AIDS and Behavior, 17, 6, 2156-61.

Kippax, S. and Race, K. (2003) Sustaining safe practice: twenty years on, Social Science \& Medicine, 57, 1, 1-12. 
Lupton, D. (2013) Risk, London, Routledge.

McCormack, S., Dunn, D.T., Desai, M., Dolling, D.I., et al. (2016) Pre-exposure prophylaxis to prevent the acquisition of HIV-1 infection (PROUD): effectiveness results from the pilot phase of a pragmatic open-label randomised trial, The Lancet, 387, 10013, 53-60.

Meloni, M., Williams, S. and Martin, P. (2016) The biosocial: sociological themes and issues, The Sociological Review Monographs, 64, 7-25.

Molina, J.M., Capitant, C., Spire, B., Pialoux, G., et al. (2015) On-demand preexposure prophylaxis in men at high risk for HIV-1 infection, New England Journal of Medicine, 373, 23, 2237-46.

Nguyen, V.K., Ako, C.Y., Niamba, P., Sylla, A., et al. (2007) Adherence as therapeutic citizenship: impact of the history of access to antiretroviral drugs on adherence to treatment, AIDS, 21, S315.

Patton, C. and Kim, H.J. (2012) The cost of science, Knowledge and ethics in HIV pre-exposure prophylaxy trials, Journal of Bioethical Inquiry, 9, 3, 295-310.

Petryna, A. (2002) Life Exposed: Biological Citizens After Chernobyl, Princeton: Princeton University Press.

Rabinow, P. (1996) Essays on the Anthropology of Reason. Princeton: Princeton University Press.

Rabinow, P. and Rose, N. (2006) Biopower today, Biosocieties, 1, 1, 195-217.

Race, K. (2001) The undetectable crisis: changing technologies of risk, Sexualities, 4, 2, 167-89.

Race, K., (2017) The Gay Science. Intimate Experiments with the Problem of HIV, London: Routledge.

Raman, S. and Tutton, R. (2010) Life, science, and biopower, Science, Technology \& Human Values, 35, 5, 711-34.

Rangel, J.C. and Adam, B.D. (2014) Everyday moral reasoning in the governmentality of HIV risk, Sociology of Health and Illness, 36, 1, 60-74.

Rose, N. and Novas, C. (2005) Biological citizenship. In Ong, A. and Collier, S. (eds) Global Assemblages: Technology, Politics and Ethics as Anthropological Problems. Oxford: Blackwell.

Rosengarten, M. and Michael, M. (2009) The performative function of expectations in translating treatment to prevention: the case of HIV pre-exposure prophylaxis, or PrEP, Social Science \& Medicine, 69, 7, 1049-55.

Rowe, M. and Dowsett, G. (2008) Sex, love, friendship, belonging and place: is there a role for "gay community" in HIV prevention today?, Culture, Health and Sexuality, 10, 4, 329-44. 
Thorne, S. (2008) Interpretive description. Walnut Creek, CA: Left Coast Press.

Vernazza, P., Hirschel, B., Bernasconi, E. and Flepp, M. (2008) Les personnes séropositives ne souffrant d'aucune autre MST et suivant un traitment antirétroviral efficace ne transmettent pas le VIH par voie sexuelle, Bulletin des Médecins Suisses, 89, 165-9.

Williams, S., Martin, P. and Gabe, J. (2011) The pharmaceuticalization of society?, A framework for analysis, Sociology of Health and Illness, 33, 5, 710-25.

Young, I., Flowers, P. and McDaid, L. (2015) Can a pill prevent HIV?, Negotiating the biomedicalisation of HIV prevention, Sociology of Health \& IIIness, 38, 3, 411-25. 